\title{
Estimation of Genetic Divergence for Growth, Earliness and Yield Parameters in Cucumber (Cucumis Sativus L.)
}

\author{
P. Shabarish Rai*, Ravindra Mulge and Siddappa Shankargouda \\ *Department of Vegetable Sciences, College of Horticulture, KRCCH, \\ Arabhavi-591218, Karnataka, India \\ *Corresponding author
}

\section{A B S T R A C T}

Fifty-six diverse genotypes of cucumber collected from different indigenous sources were planted in randomized block design, during kharif season at Kittur Rani Chennamma

\section{Keywords}

Genetic diversity,

Clusterbean,

Tocher's method,

Intra and inter

cluster distance

Article Info

Accepted:

18 April 2018

Available Online:

10 May 2018
College of Horticulture, Arabhavi, Belagavi district (Karnataka), India. Genetic diversity study using Mahalanobis's $D^{2}$ statistics with Tocher's method, 56 cucumber genotypes were grouped into ten clusters, cluster I was the largest having 26 genotypes followed by cluster III (10 genotypes) followed by cluster II (six genotypes). Among ten clusters, cluster VIII with two numbers of genotypes had maximum intra cluster distance followed by cluster V and Cluster VII. Based on the distance between the clusters i.e., inter-cluster distance, maximum divergence was observed between cluster IV and VIII, followed by Cluster IV and IX, this indicated wide range of variability among clusters. Among 18 characters studies in $\mathrm{D}^{2}$ analysis fruit yield per hectare $(22.34 \%)$ contributed maximum towards expression of genetic divergence followed by average fruit weight $(17.21 \%)$, number of fruits per vine $(14.09 \%)$, number of branches per vine $(9.42 \%)$ and days to first harvest $(9.22 \%)$. On the basis of intercluster distance and per se performance observed in the present study a hybridization programme involving genotypes for a specific character be chosen using cluster mean.

\section{Introduction}

Cucumber (Cucumis sativus L.) is a member of the family Cucurbitaceae, with chromosome number of $2 n=14$. It is a highly cross-pollinated crop and usually monoecious in nature preferring warm weather and bright light for its better growth and development. Poor yield is the major concern in cucumber cultivation. The reduced marketability of the fruit is due to the misshapen fruits. In spite of the extensive cultivation and consumption, cucumbers have not much been taken up for systematic research work in order to understand the genetic architecture and endeavor in crop improvement programs in India. Generally diverse germplasm is expected to give high hybrid vigour and hence, it necessitates the study of genetic divergence among the existing varieties and genotypes for the identification of parents for hybridization programme. The information on genetic divergence of various traits particularly of those that contribute to yield 
and quality would be of most useful in planning the breeding programme. The $\mathrm{D}^{2}$ statistics developed by Mahalanobis (1936) provides a measure of magnitude for divergence between two genotypes under comparison. Grouping of genotypes based on $\mathrm{D}^{2}$ analysis will be useful in choosing suitable parental lines for heterosis breeding.

\section{Materials and Methods}

The present investigation was carried out at during kharif season at farm unit, Kittur Rani Chennamma College of Horticulture, Arabhavi, Belagavi district (Karnataka), India. The experimental material consisted of diverse group of 56 cucumber genotypes collected from different sources. The experiment was laid out in randomised block design with two replications of each genotypes. Seeds were sown in rows spaced $1.5 \mathrm{~m}$ with spacing between plants. Regular cultural practices were followed as per package of practices of horticultural crops of University of Horticultural Sciences, Bagalkot. For recording various observations five plants in each experimental plot were selected. Observations recorded in the present investigation were Number of branches per vine, internodal length, number of leaves per vine, days to first male flowering, days to first female flowering, days to 50 per cent flowering, nodes upto first female flower, days to first harvest, days to last harvest, sex ratio (m:f), fruit length $(\mathrm{cm})$, fruit width $(\mathrm{cm})$, pericarp thickness $(\mathrm{mm})$, number of fruits per vine, average fruit weight $(\mathrm{g})$, fruit yield per vine $(\mathrm{g})$ and fruit yield per hectare $(\mathrm{t} / \mathrm{ha})$. The average data was subjected for statistical analysis and Mahalanobis $D^{2}(1936)$ statistics was used to study genetic divergence.

\section{Results and Discussion}

Fifty-six genotypes were grouped into 10 clusters (Table 1 ). Intra cluster $\mathrm{D}^{2}$ values ranged from 0.00 to 3342.35 . Among the 10 clusters, cluster VIII with two number of genotypes had maximum intra cluster diversity $\left(\mathrm{D}^{2}=3342.35\right)$ followed by cluster $\mathrm{V}$ $\left(\mathrm{D}^{2}=2632.24\right)$, Cluster VII $\left(\mathrm{D}^{2}=2612.05\right)$, cluster VI $\left(\mathrm{D}^{2}=2604.77\right)$, cluster II $\left(\mathrm{D}^{2}\right.$ $=2558.80)$, cluster III $\left(\mathrm{D}^{2}=2430.87\right)$, cluster I $\left(\mathrm{D}^{2}=1622.97\right)$ and cluster IV $\left(\mathrm{D}^{2}=914.87\right)$. Cluster IX and X had only one genotype and hence, the intra cluster distance was zero (Table 2). Similar reports were observed by Hanchinamani (2006) in cucumber. The genotypes within the same cluster although formed specific cluster but were collected from different places. The clustering pattern of the genotypes revealed that the genotypes collected from the same place did not form a single cluster. This indicated that geographic diversity was not always related to genetic diversity. Grouping of materials of same origin into different clusters was an indication of broad genetic base of the genotypes belonging to that origin.

Based on the distance between the clusters i.e., inter-cluster distance (Table 2), the maximum divergence was observed between cluster IV and VIII ( $\left.\mathrm{D}^{2}=19935.07\right)$, followed by Cluster IV and IX $\left(\mathrm{D}^{2}=14202.20\right)$, cluster IV and $X\left(D^{2}=11460.75\right)$ and cluster VI and VIII $\left(D^{2}=11291.05\right)$. Whereas, Cluster I and $\mathrm{V}\left(\mathrm{D}^{2}=2267.22\right)$ shown least inter cluster distance. The diverse genotypes characterized by maximum inter cluster distance will differ in phenotypic performance and therefore, selection of divergent parents should be based on these cluster distances to obtain favorable hybrids and transgressive segregants in cucumber. Hence apart from selecting genotypes from clusters which have high inter cluster distance for hybridization, one can also think of selecting parents based on extent of genetic divergence in respect to a particular character of interest. This mainly depending upon breeder's intention to improve particular character, i.e., yield, fruit size or pericarp 
thickness, so one can select parents which are highly divergent with respect to these characters. Earlier Khan (2006) and Ram (2001) have also indicated the significance of genetic divergence in pointed gourd.

The clusters have been formed based on the contribution (Table 3) of different characters to the divergence which includes fruit yield per hectare $(22.34 \%)$ contributing maximum to the genetic diversity among the characters followed by average fruit weight $(17.21 \%)$, number of fruits per vine (14.09\%), number of branches per vine $(9.42 \%)$, days to first harvest $(9.22 \%)$, internodal length $(5.00 \%)$, fruit length $(5.00 \%)$, nodes upto first female flower $(4.81 \%)$, number of leaves per vine $(3.90 \%)$ and yield per vine $(3.70 \%)$. However, there was no substantial contribution from the traits viz., pericarp thickness $(1.75 \%)$, vine length (1.10), days to first male flowering $(0.78 \%)$, fruit width $(0.71 \%)$, days to first female flowering $(0.65$ $\%)$, days to 50 per cent flowering $(0.52 \%)$, days to last harvest $(0.19 \%)$ and sex ratio $(0.20 \%)$. Hanchimani (2006) reported higher contribution of number of fruits per vine, fruit length, average fruit weight and yield per vine towards clustering in cucumber.

Table.1 Clustering pattern of 56 genotypes of cucumber based on $\mathrm{D}^{2}$ values

\begin{tabular}{|l|c|l|}
\hline Cluster number & $\begin{array}{c}\text { Number of } \\
\text { genotypes }\end{array}$ & \multicolumn{1}{|c|}{ Genotypes included } \\
\hline Cluster I & 26 & $\begin{array}{l}\text { ACS12-1, ACS12-2, ACS12-3, ACS12-4, ACS12-5, } \\
\text { ACS12-6, ACS12-7, ACS12-8, ACS12-9, ACS12-10, } \\
\text { ACS12-11, ACS12-12, ACS12-13, ACS12-14, ACS12- } \\
\text { 14, ACS12-16, ACS12-17, ACS12-18, ACS12-19, } \\
\text { ACS12-20, ACS12-21, ACS12-22, ACS12-23, ACS12- } \\
\text { 24, ACS12-25, ACS12-26 }\end{array}$ \\
\hline Cluster II & 6 & $\begin{array}{l}\text { ACS12-27, ACS12-28, ACS12-29, ACS12-30, ACS12- } \\
\text { 34, ACS12-38 }\end{array}$ \\
\hline Cluster III & 10 & $\begin{array}{l}\text { ACS12-31, ACS12-41, ACS12-33, ACS12-35, ACS12- } \\
\text { 36, ACS12-37, ACS12-39, ACS12-40, ACS12-41, } \\
\text { ACS12-42 }\end{array}$ \\
\hline Cluster IV & 2 & ACS12-44, ACS12-49 \\
\hline Cluster V & 3 & ACS12-45, ACS12-46, ACS12-53 \\
\hline Cluster VI & 2 & ACS12-47, ACS12-50 \\
\hline Cluster VII & 2 & ACS12-52, ACS12-55 \\
\hline Cluster VIII & 2 & ACS12-51, ACS12-56 \\
\hline Cluster IX & 1 & ACS12-48 \\
\hline Cluster X & 1 & ACS12-54 \\
\hline
\end{tabular}


Table.2 Average intra and inter-clusters $\mathrm{D}^{2}$ values along with their ' $\mathrm{D}$ ' values (In parenthesis) of 10 clusters for 18 characters formed by 56 genotypes of cucumber

\begin{tabular}{|c|c|c|c|c|c|c|c|c|c|c|}
\hline & I & II & III & IV & $\mathbf{V}$ & VI & VII & VIII & IX & $\mathbf{X}$ \\
\hline I & $\begin{array}{c}1622.97 \\
(40.28)\end{array}$ & $\begin{array}{c}2376.77 \\
(48.75)\end{array}$ & $\begin{array}{c}2305.16 \\
(48.01)\end{array}$ & $\begin{array}{c}7894.53 \\
(88.85)\end{array}$ & $\begin{array}{c}2267.22 \\
(47.62)\end{array}$ & $\begin{array}{c}3665.85 \\
(60.55)\end{array}$ & $\begin{array}{c}6656.64 \\
(81.58)\end{array}$ & $\begin{array}{c}9147.05 \\
(95.64)\end{array}$ & $\begin{array}{c}4608.68 \\
(67.88)\end{array}$ & $\begin{array}{c}3120.03 \\
(55.85)\end{array}$ \\
\hline II & & $\begin{array}{c}2558.80 \\
(50.58)\end{array}$ & $\begin{array}{c}(2630.39 \\
(51.28)\end{array}$ & $\begin{array}{c}6029.89 \\
(77.65)\end{array}$ & $\begin{array}{c}2750.14 \\
(52.44)\end{array}$ & $\begin{array}{c}3381.98 \\
(58.15)\end{array}$ & $\begin{array}{c}6710.75 \\
(81.91)\end{array}$ & $\begin{array}{c}10837.46 \\
(104.10)\end{array}$ & $\begin{array}{c}6233.12 \\
(78.95)\end{array}$ & $\begin{array}{c}3759.86 \\
(61.32)\end{array}$ \\
\hline III & & & $\begin{array}{c}2430.87 \\
(49.30)\end{array}$ & $\begin{array}{c}6236.17 \\
(78.96)\end{array}$ & $\begin{array}{c}2557.95 \\
(50.57)\end{array}$ & $\begin{array}{c}2941.86 \\
(54.24)\end{array}$ & $\begin{array}{c}5057.30 \\
(71.12)\end{array}$ & $\begin{array}{c}8907.91 \\
(94.38)\end{array}$ & $\begin{array}{c}5211.62 \\
(72.19)\end{array}$ & $\begin{array}{c}3642.73 \\
(60.35)\end{array}$ \\
\hline IV & & & & $\begin{array}{l}914.87 \\
(30.25)\end{array}$ & $\begin{array}{c}8375.93 \\
(91.52)\end{array}$ & $\begin{array}{c}3842.13 \\
(61.98)\end{array}$ & $\begin{array}{c}5578.55 \\
(74.69)\end{array}$ & $\begin{array}{c}19935.07 \\
(141.19)\end{array}$ & $\begin{array}{c}14202.20 \\
(119.17)\end{array}$ & $\begin{array}{c}11460.75 \\
(107.05)\end{array}$ \\
\hline $\mathbf{V}$ & & & & & $\begin{array}{c}2632.24 \\
(51.31)\end{array}$ & $\begin{array}{c}3726.31 \\
(61.04)\end{array}$ & $\begin{array}{c}5649.48 \\
(75.16)\end{array}$ & $\begin{array}{c}7307.18 \\
(85.48)\end{array}$ & $\begin{array}{c}2685.25 \\
(62.36)\end{array}$ & $\begin{array}{c}2685.25 \\
(51.82)\end{array}$ \\
\hline VI & & & & & & $\begin{array}{c}2604.77 \\
(51.04)\end{array}$ & $\begin{array}{c}4254.00 \\
(65.22)\end{array}$ & $\begin{array}{c}11291.05 \\
(106.26)\end{array}$ & $\begin{array}{c}5568.95 \\
(71.49)\end{array}$ & $\begin{array}{c}5568.96 \\
(74.63)\end{array}$ \\
\hline VII & & & & & & & $\begin{array}{c}2612.05 \\
(51.11)\end{array}$ & $\begin{array}{c}9569.16 \\
(97.82)\end{array}$ & $\begin{array}{c}8362.33 \\
(95.07)\end{array}$ & $\begin{array}{c}8362.33 \\
(91.45)\end{array}$ \\
\hline VIII & & & & & & & & $\begin{array}{c}3342.35 \\
(57.81)\end{array}$ & $\begin{array}{c}4798.13 \\
(79.99)\end{array}$ & $\begin{array}{c}4798.13 \\
(69.57)\end{array}$ \\
\hline IX & & & & & & & & & $\begin{array}{c}0.00 \\
(0.00)\end{array}$ & $\begin{array}{c}3976.06 \\
(63.05)\end{array}$ \\
\hline $\mathbf{X}$ & & & & & & & & & & $0.00(0.000)$ \\
\hline
\end{tabular}

Diagonal values (bold) indicates the intra cluster distances 
Table.3 Relative per cent contribution of different characters to divergence in cucumber

\begin{tabular}{|c|c|c|c|}
\hline $\begin{array}{l}\text { Sl. } \\
\text { No. }\end{array}$ & Characters & $\begin{array}{l}\text { Number of times } \\
\text { ranked first }\end{array}$ & $\begin{array}{c}\text { Per cent } \\
\text { contribution }\end{array}$ \\
\hline 1 & Vine length & 17.00 & 1.10 \\
\hline 2 & Number of branches per vine & 145.00 & 9.42 \\
\hline 3 & Internodal length & 77.00 & 5.00 \\
\hline 4 & Number of leaves per vine & 60.00 & 3.90 \\
\hline 5 & Days to first male flowering & 12.00 & 0.78 \\
\hline 6 & Days to first female flowering & 1.00 & 0.65 \\
\hline 7 & Days to $50 \%$ flowering & 8.00 & 0.52 \\
\hline 8 & Nodes upto first female flower & 74.00 & 4.81 \\
\hline 9 & Days to first harvest & 142.00 & 9.22 \\
\hline 10 & Days to last harvest & 3.00 & 0.19 \\
\hline 11 & Sex Ratio & 3.00 & 0.20 \\
\hline 12 & Fruit length $(\mathrm{cm})$ & 77.00 & 5.00 \\
\hline 13 & Fruit width $(\mathrm{cm})$ & 11.00 & 0.71 \\
\hline 14 & Pericarp thickness (mm) & 27.00 & 1.75 \\
\hline 15 & Number of fruits per vine & 217.00 & 14.09 \\
\hline 16 & Average fruit weight (g) & 265.00 & 17.21 \\
\hline 17 & Fruit yield per vine (g) & 57.00 & 3.70 \\
\hline \multirow[t]{2}{*}{18} & Fruit yield per hectare (t/ha) & 344.00 & 22.34 \\
\hline & Total & 1540 & 100.00 \\
\hline
\end{tabular}


Table. 4 The mean values of 18 characters for 10 clusters formed by56 genotypes in cucumber

\begin{tabular}{|c|c|c|c|c|c|c|c|c|c|c|c|}
\hline $\begin{array}{c}\text { Sl. } \\
\text { No. }\end{array}$ & Characters & $\mathbf{I}$ & II & III & IV & $\mathbf{V}$ & VI & VII & VIII & IX & $\mathbf{X}$ \\
\hline 1 & Vine Length & 134.57 & 116.51 & 120.16 & 91.95 & 128.88 & 120.25 & 162.63 & 174.00 & 120.75 & 116.25 \\
\hline 2 & Number of branches per vine & 3.85 & 3.63 & 4.11 & 2.50 & 4.38 & 3.50 & 4.50 & 7.33 & 5.00 & 5.40 \\
\hline 3 & Internodal length & 5.36 & 5.55 & 6.35 & 8.20 & 6.87 & 6.99 & 11.70 & 8.15 & 6.18 & 3.90 \\
\hline 4 & Number of leaves per vine & 95.68 & 80.65 & 96.49 & 62.22 & 112.22 & 124.10 & 96.60 & 158.75 & 203.55 & 115.20 \\
\hline 5 & Days to first male flowering & 35.34 & 39.28 & 38.55 & 44.95 & 35.96 & 40.45 & 38.30 & 34.85 & 32.80 & 39.10 \\
\hline 6 & Days to first female flowering & 42.65 & 46.58 & 46.85 & 52.25 & 43.27 & 47.75 & 45.60 & 42.15 & 40.10 & 46.40 \\
\hline 7 & Days to $50 \%$ flowering & 42.57 & 45.86 & 46.70 & 55.70 & 45.47 & 48.35 & 50.10 & 50.35 & 38.60 & 47.50 \\
\hline 8 & Nodes upto first female flowering & 4.24 & 3.93 & 4.35 & 5.80 & 3.10 & 4.40 & 4.70 & 6.20 & 3.70 & 6.00 \\
\hline 9 & Days to first harvest & 58.31 & 59.55 & 61.09 & 68.50 & 57.66 & 61.85 & 58.75 & 61.85 & 54.40 & 61.00 \\
\hline 10 & Days to last harvest & 90.89 & 92.89 & 92.75 & 90.24 & 84.90 & 92.80 & 91.15 & 89.75 & 96.60 & 95.40 \\
\hline 11 & Sex Ratio & 6.66 & 4.92 & 6.48 & 7.66 & 7.82 & 12.28 & 10.01 & 8.23 & 19.26 & 9.23 \\
\hline 12 & Fruit length $(\mathrm{cm})$ & 16.55 & 13.13 & 16.88 & 17.50 & 12.54 & 14.60 & 19.20 & 11.29 & 15.00 & 6.46 \\
\hline 13 & Fruit width $(\mathrm{cm})$ & 4.56 & 5.17 & 5.27 & 7.37 & 4.65 & 6.86 & 7.41 & 5.14 & 5.36 & 4.18 \\
\hline 14 & Pericarp thickness (mm) & 9.71 & 12.23 & 12.75 & 16.45 & 8.88 & 16.75 & 15.15 & 8.96 & 11.61 & 4.92 \\
\hline 15 & Number of fruits per vine & 9.66 & 13.15 & 9.72 & 4.75 & 13.03 & 6.15 & 5.60 & 20.10 & 12.30 & 8.40 \\
\hline 16 & Average fruit weight $(\mathrm{g})$ & 156.82 & 122.35 & 168.79 & 183.25 & 111.90 & 171.20 & 197.85 & 86.10 & 102.40 & 45.50 \\
\hline 17 & Fruit yield per vine(g) & 1468.67 & 1405.30 & 1493.71 & 900.80 & 1276.53 & 1095.75 & 1113.60 & 1306.45 & 722.30 & 368.40 \\
\hline 18 & fruit yield per hectare(t/ha) & 13.08 & 12.48 & 12.27 & 8.01 & 11.35 & 9.74 & 9.89 & 11.61 & 6.42 & 3.27 \\
\hline
\end{tabular}


For vine length (Table 4), highest cluster mean was observed in cluster VIII, followed by cluster VII, cluster I and cluster V. Inter cluster distance between Cluster VIII and Cluster VII $\left(\mathrm{D}^{2}=9569.16\right)$, cluster VIII and cluster I $\left(\mathrm{D}^{2}=9147.05\right)$, cluster VIII and cluster V $\left(D^{2}=7307.18\right)$ were comparatively high and hence, the hybridization programme may be employed between the genotypes of these clusters to increase vine length.

For number of branches per vine (Table 4), highest cluster mean was observed in the cluster VIII followed by cluster $\mathrm{X}$ and cluster IX. Inter cluster distance between cluster VIII and cluster $\mathrm{X}\left(\mathrm{D}^{2}=4839.98\right)$ and cluster VIII and cluster IX $\quad\left(\mathrm{D}^{2}=4798.13\right)$ were comparatively high and hence, the hybridization programme may be employed between the genotypes of these clusters to improve number of branches per vine.

For internodal length, lowest cluster mean (Table 4) was observed in the cluster $X$, followed by cluster I, cluster II and cluster IX. Inter cluster distance cluster VII and cluster VIII $\left(\left(D^{2}=9569.16\right)\right.$, cluster VII and cluster IV $\left(\mathrm{D}^{2}=5578.55\right)$, cluster VII and cluster VI $\left(D^{2}=4254.00\right)$, were comparatively high and genotypes between these clusters can be utilized to decrease internodal length in hybridization. For number of leaves per vine, highest cluster mean (Table 4) was observed in the cluster IX, followed by cluster VIII and cluster VI. Inter cluster distance between cluster IX and cluster VI $\left(D^{2}=5568.95\right)$ and cluster IX and cluster VIII $\left(D^{2}=4798.13\right)$, were comparatively high and genotypes between these clusters can be utilized in hybridization programme to increase number of leaves and in turn to produce more yield.

For days to first male flowering, lowest value is preferred, lower cluster mean (Table 4) was observed in the cluster IX, followed by the cluster VIII and cluster I. Inter cluster distance between cluster IX and cluster VIII
$\left(\mathrm{D}^{2}=4798.13\right)$ and between cluster IX and cluster I $\left(\mathrm{D}^{2}=4608.68\right)$, were comparatively high. Hence, hybridization between genotypes of these clusters would be worth to be attempted to enhance earliness. For days to first female flowering, lowest cluster mean (Table 4) was observed in the cluster IX, followed by cluster VIII, cluster I and cluster $\mathrm{V}$. Inter cluster distance cluster IX and cluster VIII $\left(D^{2}=4798.13\right)$, cluster IX and cluster I $\left(D^{2}=4608.68\right)$ and between cluster IX and cluster V $\left(\mathrm{D}^{2}=2685.25\right)$ were comparatively high. Hence, hybridization between genotypes of these clusters would be worth to be attempted to enhance earliness.

For character days to 50 per cent flowering lowest cluster mean (Table 4) was observed in the cluster IX, followed by cluster I, cluster V. Inter cluster distance between cluster IX and cluster I $\left(D^{2}=4608.68\right)$ and cluster IX and cluster V $\left(D^{2}=2685.25\right)$ were comparatively high. Hence, hybridization between genotypes of these clusters would be helpful to enhance earliness.

For trait, nodes up to first female flowering, lowest cluster mean (Table 4) was observed in the cluster $\mathrm{V}$ followed by cluster IX and cluster II. Inter cluster distance between cluster V and cluster II $\left(\mathrm{D}^{2}=2750.14\right)$ and cluster V and cluster IX $\left(D^{2}=2685.25\right)$, were comparatively high. Hence, hybridization between genotypes of these clusters would be attempted to achieve early nodes to bear female flowers.

For days to first harvest, lowest cluster mean (Table 4) was observed in the cluster IX, followed by cluster $\mathrm{V}$ and cluster I. Inter cluster distance between cluster IX and cluster I $\left(D^{2}=4608.68\right)$ and cluster IX and cluster V $\left(D^{2}=2685.25\right)$, were comparatively high. Hence, hybridization between genotypes of these clusters would be worth to be attempted to improve early harvest. 
Sex ratio is calculated as number of male to female flowers and hence lower value is preferred. The lowest cluster mean (Table 4) for sex ratio was observed in cluster II followed by cluster III, cluster I and cluster IV. Inter cluster distance between cluster II and cluster IV $\left(\mathrm{D}^{2}=6029.89\right)$, cluster II and cluster III $\left(\mathrm{D}^{2}=2630.39\right)$ and cluster II and cluster I $\left(D^{2}=2376.77\right)$ were comparatively high. Hence, crosses between the genotypes of these respective clusters can be attempted to improve sex ratio, to get more number of fruits, which would ultimately help in yield improvement.

For fruit length, highest cluster mean (Table 4) was observed in the cluster VII followed by cluster IV, cluster III, cluster I. Inter cluster distance between cluster VII and cluster I $\left(D^{2}=6656.64\right)$, cluster VII and cluster IV $\left(D^{2}=5578.55\right)$ and cluster VII and cluster III $\left(D^{2}=5057.30\right)$, were comparatively high. Hence, crosses between the genotypes of these respective clusters can be attempted to get longer fruits.

For fruit width, highest cluster mean (Table 4) was observed in the cluster VII followed by cluster IV, cluster VI and cluster IX. Inter cluster distance between cluster VII and cluster IX $\left(D^{2}=6656.64\right)$, cluster VII and cluster IV $\left(\mathrm{D}^{2}=5578.55\right)$ and cluster VII and cluster VI $\left(D^{2}=4254.00\right)$, were comparatively high. Hence, crosses between the genotypes of these respective clusters can be attempted to increase for fruit width.

For pericarp thickness, highest cluster mean (Table 4) was observed in the cluster VI followed by cluster IV and cluster VII. Inter cluster distance between cluster VI and cluster VII $\left(D^{2}=4254.00\right)$ and cluster VI and cluster IV $\left(D^{2}=3842.13\right)$, were comparatively high. Hence, crosses between the genotypes of these respective clusters can be attempted to improve pericarp thickness.
For number of fruits per vine highest cluster mean (Table 4) was observed in the cluster VIII followed by cluster II, cluster V, cluster IX. Inter cluster distance between cluster VIII and cluster II $\left(D^{2}=10837.46\right)$, cluster VIII and cluster V $\left(\mathrm{D}^{2}=7307.4\right)$ and cluster VIII and cluster IX $\left(D^{2}=4798.13\right)$ were comparatively high. Hence, crosses between the genotypes of these respective clusters can be attempted to get more number of fruits per vine.

For average fruit weight, highest cluster mean (Table 4) was observed in the cluster VII followed by cluster IV, cluster VI and cluster III. Inter cluster distance between cluster VII and cluster IV $\left(D^{2}=5578.55\right)$, cluster VII and cluster III $\left(D^{2}=5057.30\right)$ and cluster VII and cluster VI $\left(D^{2}=4254.00\right)$ were comparatively high. Hence, the crosses between the genotypes of these respective clusters may be tried for improvement of average fruit weight, which ultimately contributes to the total yield.

For fruit yield per vine highest cluster mean (Table 4) was observed in the cluster III followed by cluster I, cluster II, cluster VIII and cluster V. Inter cluster distance between cluster III and cluster II $\left(D^{2}=2630.39\right)$, cluster III and cluster V $\left(D^{2}=2557.95\right)$ and cluster III and cluster I $\left(D^{2}=2305.16\right)$. Hence, the crosses between the genotypes of these respective clusters may be attempted for increasing yield per vine and yield per hectare. For crop improvement, inter-crossing among genotypes with outstanding mean performance was suggested by Roy and Sharma (1996).

\section{References}

Hanchinamani, C. N. 2006. Genetic variability, divergence, heterosis and combining ability studies in cucumber (Cucumis sativus L.). Ph.D. (Hort.) Thesis, UAS, Dharwad.

Mahalanobis, P. C. 1936. Proceedings of the National Academy of Sciences on the 
generalized distance in statistics, 19: Ram, D. 2001. Non-Hirachical Euclidean 201-208.

Khan, A.S.M.M.R. 2006. Study on genetic diversity and production technology of pointed gourd. Ph.D. Thesis, Bangladesh Agricultural University, Mymensingh, Bangladesh. Cluster analysis in pointed gourd. Indian J. Hort. 58(3): 264-268.

Roy, A. and Sharma, R.N. 1996. Multivariate analysis in chilli (Capsicum annum L.). Annals Agric. Res. 17(1): 30-32.

\section{How to cite this article:}

Shabarish Rai, P., Ravindra Mulge and Siddappa Shankargouda. 2018. Estimation of Genetic Divergence for Growth, Earliness and Yield Parameters in Cucumber (Cucumis Sativus L.). Int.J.Curr.Microbiol.App.Sci. 7(05): 2374-2382. doi: https://doi.org/10.20546/ijcmas.2018.705.273 